\title{
Anti-inflammatory property of Parkia speciosa empty pod extract in human umbilical vein endothelial cells
}

\author{
Nor-Hidayah Mustafa ${ }^{1}$, Azizah Ugusman ${ }^{2}$, Juriyati Jalil ${ }^{3}$, Yusof Kamisah ${ }^{1}$. \\ ${ }^{1}$ Department of Pharmacology, Faculty of Medicine, UKMMC, Universiti Kebangsaan Malaysia, Jalan Yaacob Latif, 56000 Cheras, Kuala Lumpur, \\ Malaysia. \\ ${ }^{2}$ Department of Physiology, Faculty of Medicine, UKMMC, Universiti Kebangsaan Malaysia, Jalan Yaakob Latif, 56000 Cheras, Kuala Lumpur, Malaysia. \\ ${ }^{3}$ Drug and Herbal Research Centre, Faculty of Pharmacy, Universiti Kebangsaan Malaysia, Jalan Raja Muda Abdul Aziz, 50300 Kuala Lumpur, Malaysia.
}

\begin{tabular}{|c|c|}
\hline ARTICLE INFO & ABSTRACT \\
\hline Article history: & \multirow{11}{*}{$\begin{array}{l}\text { Parkia speciosa Hassk, locally known as petai papan, is a common medicinal plant found in Southeast Asia. Its } \\
\text { empty pods were reported to contain high concentrations of polyphenols, particularly quercetin. This study } \\
\text { aimed to evaluate the anti-inflammatory properties of } P \text {. speciosa empty pod extract in human umbilical vein } \\
\text { endothelial cells (HUVECs). The empty pods were extracted by sequential fractionation with absolute ethanol } \\
\text { and ethyl acetate. HUVECs were divided into four groups. HUVECs were exposed to tumor necrosis factor- } \alpha \\
\text { (TNF- } \alpha, 10 \mathrm{ng} / \mathrm{mL} \text { ) in the presence }(25 \mu \mathrm{g} / \mathrm{mL} \text { ) or absence of Parkia speciosa extract. Quercetin }(125 \mu \mathrm{M}) \\
\text { served as the positive control, while another group that was not exposed to TNF- } \alpha \text { acted as the negative control. } \\
\text { The protein expressions of the inflammatory mediators, which were NF- } \mathrm{B} \text { p p65, iNOS, COX-2 and VCAM-1, } \\
\text { were significantly decreased in the } P \text {. speciosa and quercetin groups exposed to TNF- } \alpha \text {. } P \text {. speciosa extract and } \\
\text { quercetin also significantly reduced intracellular reactive oxygen species and nitric oxide levels as well as } \\
\text { inducible nitric oxide synthase (iNOS) activity caused by TNF- } \alpha \text { in HUVECs. In conclusion, P. speciosa empty } \\
\text { pod extract exhibited potential anti-inflammatory properties against TNF- } \alpha \text {-induced inflammation, possibly by } \\
\text { modulating the NF- } \kappa \text { B p } 65 \text { pathway. The effects were comparable to that of quercetin. }\end{array}$} \\
\hline Received on: 15/09/2017 & \\
\hline Accepted on: 26/11/2017 & \\
\hline Available online: $28 / 01 / 2018$ & \\
\hline Key words: & \\
\hline NF-кB p65, vascular cell & \\
\hline adhesion molecule, reactive & \\
\hline oxygen species, inducible & \\
\hline nitric oxide synthase, & \\
\hline cyclooxygenase- 2 & \\
\hline & \\
\hline
\end{tabular}

\section{INTRODUCTION}

The pathogenesis of many diseases, such as atherosclerosis, hypertension and diabetic vasculopathy, involves inflammation (He et al., 2015). Inflammation leads to cellular and tissue injuries. Nuclear factor $\kappa B(N F-\kappa B)$ signaling is believed to be featured in the inflammatory cascade (Hsu et al., 2013), resulting in an increase in vascular cell adhesion molecule-1 (VCAM-1) (Conde et al., 2017), inducible nitric oxide synthase (iNOS) and cyclooxygenase-2 (COX-2) expression as well as proinflammatory cytokines, like tumor necrosis factor- $\alpha$ (TNF- $\alpha$ ) (Hsu et al., 2013). Elevated expression of iNOS will increase nitric oxide (NO) and reactive oxygen

\footnotetext{
* Corresponding Author

Yusof Kamisah, PhD Department of Pharmacology, Faculty of Medicine, UKMMC, UniversitiKebangsaan Malaysia, JalanYaacob Latif, Bandar TunRazak, 56000 Cheras, Kuala Lumpur, Malaysia Tel: +603-91459575; Fax: +603-91459547

Email:kamisah_y@yahoo.com
}

species production (Hsu et al., 2013). TNF- $\alpha$ has been employed in many studies to evoke inflammatory reactions in cultured cells (Cao et al., 2009; Qi et al., 2010). Many studies have shown that plants with polyphenol compounds possess anti-inflammatory properties (Diaz-Rivas et al., 2015; Tuzcu et al., 2017). Parkia speciosa Hassk or stink bean, a plant indigenous to Southeast Asia and locally known as petai papan from the family Leguminosae, was reported to contain high levels of polyphenol compounds, particularly in its empty pods (Kamisah et al., 2013; Ko et al., 2014).

It has been utilized in folk medicine to control hypertension (Lim, 2012). Previously, it was shown that there is prevention of hypertension in rats administered with $\mathrm{N}(\mathrm{G})$-nitro-Larginine methyl ester, an inhibitor of nitric oxide synthase (Kamisah et al. 2017). Based on this, the current study was conducted to investigate the effects of $P$. speciosa empty pods on TNF- $\alpha$-induced inflammation in human umbilical vein endothelial cells (HUVECs). 


\section{MATERIALS AND METHODS}

\section{Plant material and extraction method}

Fresh empty pods of $P$. speciosa were collected from Bidor (Perak, Malaysia) in December 2014. Its voucher specimen (UKMB 40239) was authenticated by a botanist and deposited at the Herbarium of Universiti Kebangsaan Malaysia Bangi, Selangor, Malaysia. De-seeded and dried empty pods were finely chopped and ground to fine powder $(1.2 \mathrm{~kg})$ with a blender and then macerated and extracted (every $24 \mathrm{~h}$ ) in absolute ethanol ( $3 \mathrm{x}$ $4 \mathrm{~L}$ ). The filtered extract was evaporated under vacuum using a rotary evaporator. The remaining crude extract was then sequentially partitioned three times with hexane and ethyl acetate. The resultant ethyl acetate extract was utilized for further study based on our preliminary work that showed its highest viability in HUVECs (unpublished data). The yield was $11.261 \%$.

\section{Phytochemical analysis of $\boldsymbol{P}$. speciosa empty pods}

High-performance liquid chromatography (HPLC) analysis was conducted to identify the polyphenolic compounds present in the ethyl acetate fractions of $P$. speciosa empty pod ethanolic extract according to the method described by Komolafe et al. (2014) with certain modifications. Briefly, the modifications were the use of a chromatographic system (Waters 2535) equipped with a reversed-phased column C-18 (4.6 x $250 \mathrm{~mm}, 5 \mu \mathrm{m}$; XBridge, Waters, Dublin, Ireland) and a photodiode array detector (Waters 2998) that was set at 254 and $365 \mathrm{~nm}$. Samples were eluted with $1 \%$ aqueous acetic acid solution (A) and acetonitrile (B) at $0.5 \mathrm{ml} / \mathrm{mL}$ with the following gradient: $13 \%$ B from 0 to 10 min that was increased to $20 \%, 30 \%, 50 \%, 70 \%$ and back to $20 \%$ $\mathrm{B}$ at $20 \mathrm{~min}, 30 \mathrm{~min}, 40 \mathrm{~min}, 50 \mathrm{~min}, 60 \mathrm{~min}$, and $80 \mathrm{~min}$, respectively.

All chromatographic procedures were carried out at ambient temperature. The peaks obtained from the elution of the extract which was dissolved in HPLC grade methanol $(10 \mathrm{mg} / \mathrm{ml})$ were confirmed by comparing the retention time with those of reference standards (gallic acid, ellagic acid, catechin and quercetin).

\section{Cell viability assay}

HUVECs (Gibco, Grand Island, NY, USA) were grown in endothelial cell media and maintained in $1 \%$ endothelial cell growth supplement according to the manufacturer's recommended protocol. Cells were passaged at confluence and only culture passages 3 to 6 were made use of in this study. 3-(4,5-Dimethylthiazol-2-yl)-5- (3-carboxymethoxyphenyl)-2(4-sulfophenyl)-2H-tetrazolium (MTS) assay was performed with the CellTiter 96 Aqueous One Solution Proliferation Assay Kit (Promega, Madison, USA) to measure cell viability.

\section{Cell culture treatment}

HUVECs were pretreated with $P$. speciosa $(25 \mu \mathrm{g} / \mathrm{mL})$ extract or quercetin $(125 \mu \mathrm{M})$ (Indra et al., 2013) for $6 \mathrm{~h}$ before being exposed to TNF- $\alpha$ (10 ng/mL; R\&D Systems, Abingdon,
UK) and actinomycin D $(1 \mu \mathrm{g} / \mathrm{mL}$; Sigma-Aldrich, USA) (ZhouStache et al., 2002) for another $16 \mathrm{~h}$. Quercetin served as the positive control. Another group without any treatment served as the negative control group.

\section{Western immunoblot analysis}

The expression of targeted proteins, which were NF-kB p65 (Santa Cruz Biotech, USA), iNOS (Abcam, USA), COX-2 (Cell Signaling, USA), VCAM-1 (Santa Cruz Biotech, USA), and $\beta$-actin (Santa Cruz Biotech, USA) were determined by Western blot analysis with the respective primary antibodies (1:1000) and secondary antibodies (1:3000) (Xie et al., 2000). Incubation with $\beta$-actin antibody was carried out as a comparative control.

\section{Measurement of intracellular ROS and NO levels as well as iNOS activity}

Intracellular ROS levels were measured via a fluorescent probe, 2',7' dichlorodihydrofluorescein (DCFH-DA, Sigma Co., USA) (Wen et al., 2013). NO levels in the cell culture medium were measured with Griess reagent (Miranda et al., 2001). Meanwhile, the activity of iNOS was determined according to the manufacturer's assay kit protocol (Elabscience, China).

\section{Statistical analysis}

All experiments were carried out in triplicate. The data were expressed as mean \pm standard error of mean (SEM). Normally distributed data were statistically analyzed through one way analysis of variance (ANOVA) followed by Tukey's post-hoc test, while non-normally distributed data was evaluated by the Kruskal-Wallis test. $P$ values $<0.05$ were considered significant.

\section{RESULTS}

\section{Phytochemical analysis}

Only two standards (catechin and quercetin) appeared when eluted at $365 \mathrm{~nm}$. There were six major peaks that appeared in the chromatogram of the extract. However, when compared with the reference standards, only quercetin was identified (Figure 1). All peaks of the reference standards (gallic acid, ellagic acid, catechin, and quercetin) appeared at 254 $\mathrm{nm}$, but no peaks appeared in the sample (data not shown). The quercetin content in the extract was $5.84 \mathrm{mg}$ per $100 \mathrm{~g}$ dry extract.

\section{Viability percentage}

TNF- $\alpha$ significantly reduced cell viability by approximately $50 \%$ when compared to the negative control (without TNF- $\alpha$ or extract). Preincubation with the extract at $12 \mu \mathrm{g} / \mathrm{ml}$ and larger concentrations significantly increased cell viability in HUVECs exposed to TNF- $\alpha$. However, no difference was noted among the groups given the extract (Figure 2). 

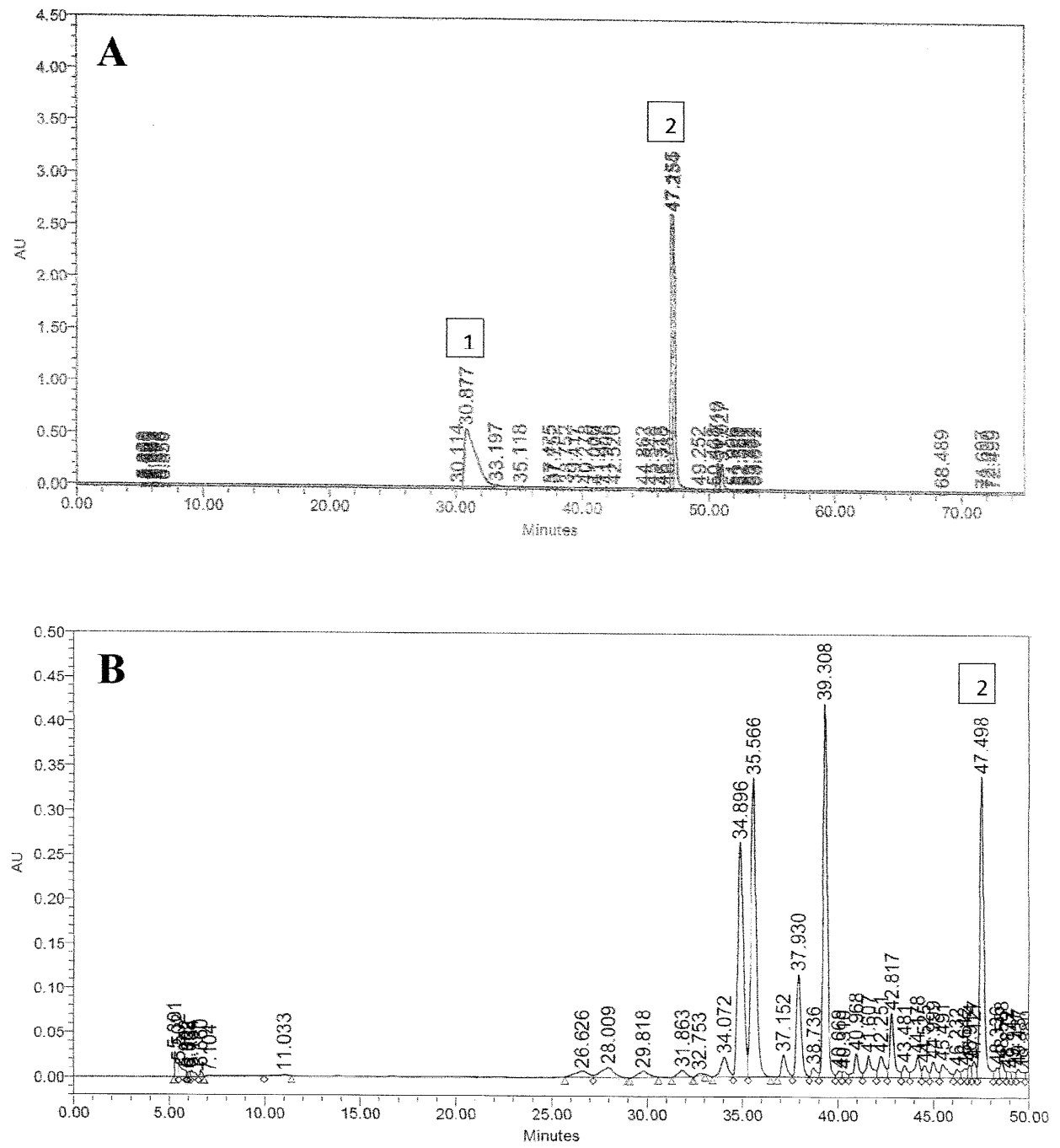

Fig. 1: Chromatogram of reference standards (A) (peak 1: catechin; peak 2: quercetin) and parkia speciosa extract (B) (peak 2: quercetin) at $365 \mathrm{~nm}$.

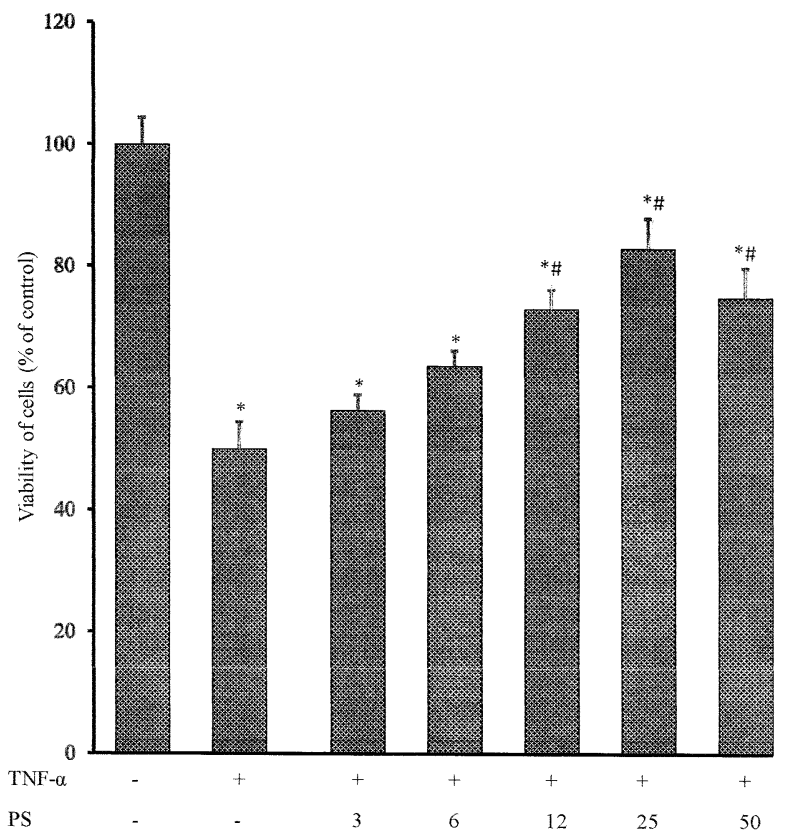

Fig. 2: effects of various doses parkia speciosa (PS) extracts $(3-50 \mu \mathrm{g} / \mathrm{mL})$ on cell viability using MTS assay after being exposed to TNF- $\alpha$ Bars represent mean $\pm \operatorname{SEM}(n=3), * P<0.05$. 
Protein expressions of NF-кB p65, iNOS, COX-2, and VCAM-1 Stimulation with $\mathrm{TNF}-\alpha$ elevated $\mathrm{NF}-\kappa \mathrm{B}$ p 65 protein expression in HUVECs compared to the negative control. $P$. speciosa and quercetin treatments significantly reduced $\mathrm{NF}-\kappa \mathrm{B}$ p65 protein expression versus the TNF- $\alpha$-induced group. The expression of $\mathrm{NF}-\kappa \mathrm{B}$ p65 in the $P$. speciosa group was significantly higher than the negative control and quercetin groups (Figure 3A). Further, TNF- $\alpha$ incubation rose iNOS protein expression in HUVECs. With this, both $P$. speciosa and quercetin groups had significantly lower iNOS protein expression in cells exposed to TNF- $\alpha$ than the TNF- $\alpha$ alone group (Figure 3B). The protein expression of COX-2 in HUVECs was significantly elevated in cells incubated with TNF- $\alpha$ compared to the negative control. Pretreatments of $P$. speciosa and quercetin significantly mitigated the effect of TNF- $\alpha$ on COX-2 protein expression. The $P$. speciosa group, but not the quercetin group, had significantly higher COX-2 protein expression than the negative control. The expression of the extract group was significantly greater than the quercetin group (Figure 4A).

VCAM-1 protein expression was significantly elevated in TNF- $\alpha$-induced group compared to the negative control. The expression of VCAM-1 in both treated groups (extract and quercetin) was significantly reduced. Moreover, no difference was evident between the extract and quercetin groups (Figure 4B).
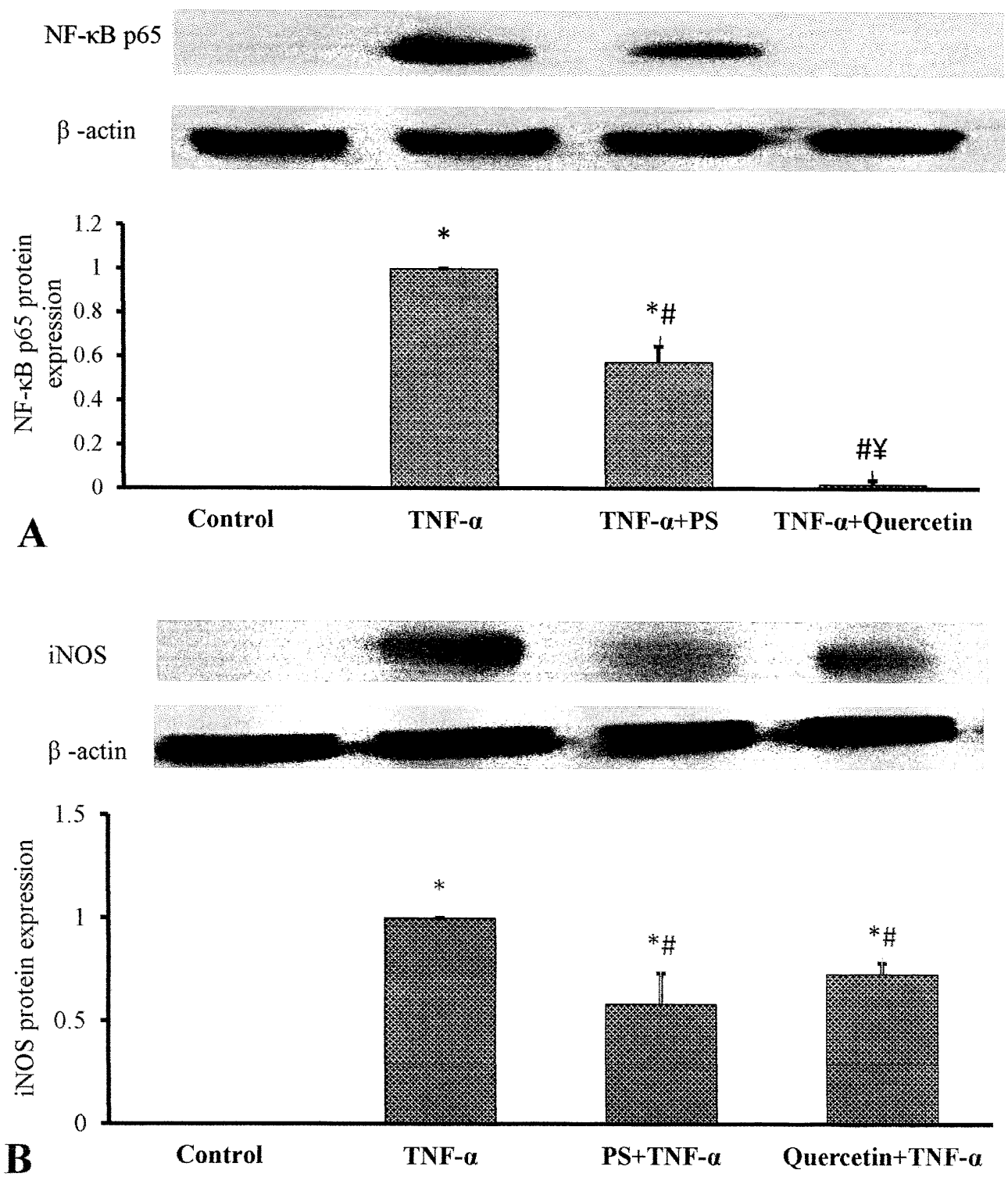

Fig. 3: Effects of parkia speciosa extract (PS, $25 \mu \mathrm{g} / \mathrm{mL})$ and quercetin $(125 \mu \mathrm{M})$ on $\mathrm{NF}-\mathrm{Kb}$ (A) and inducible nitric oxide synthase (Inos) (B) protein expression in TNF- $\alpha$-activated $(10 \mathrm{ng} / \mathrm{ml})$ HUVECs. The data were expressed as means \pm SEM $(\mathrm{n}=3)$, ${ }^{*} \mathrm{P}<0.05$ vs control, \#P $<0.05$ vs TNF- $\alpha$. 


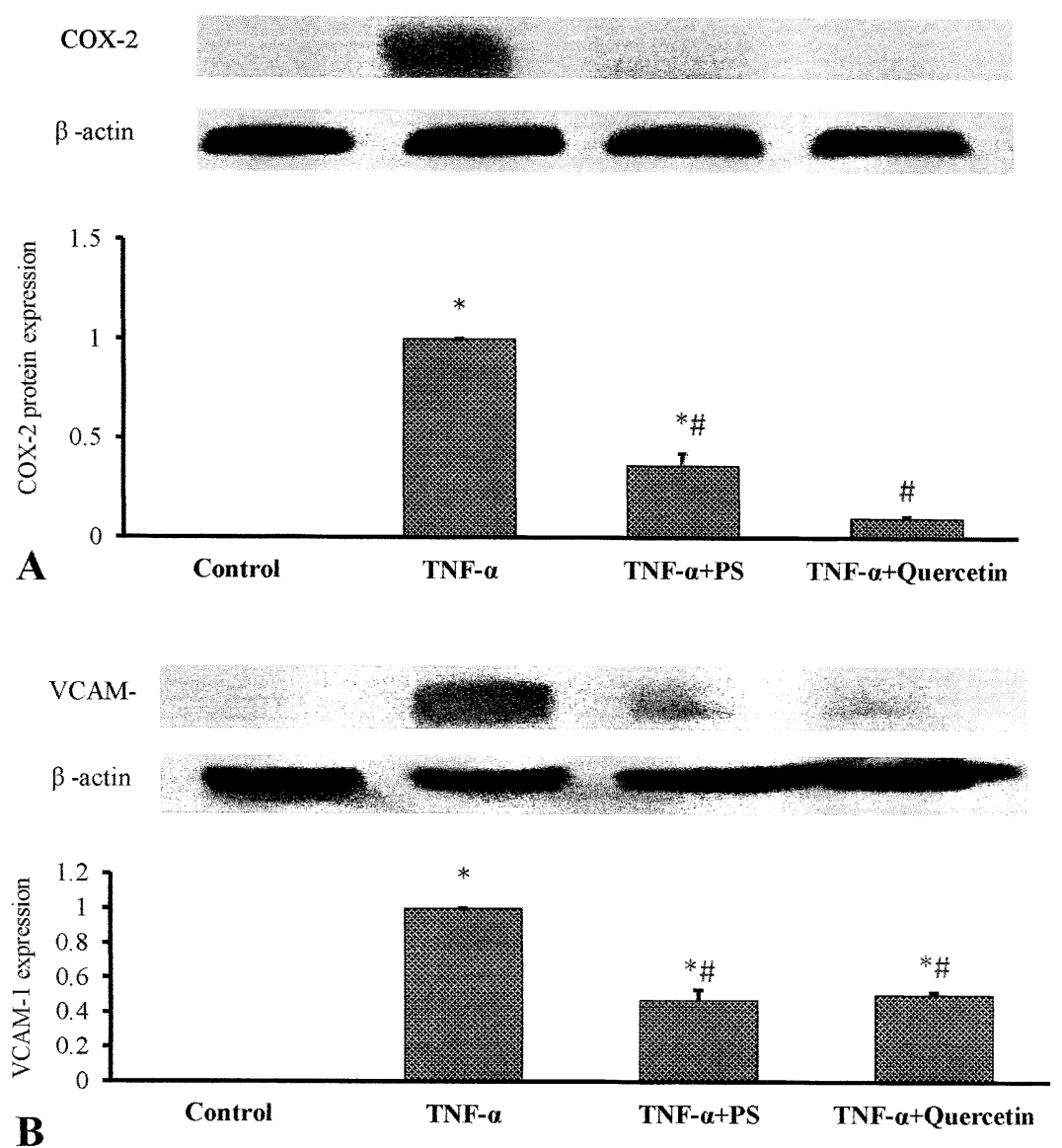

Fig. 4: Effects of parkia speciosa extract (PS, $25 \mu \mathrm{g} / \mathrm{mL})$ querectin $(125 \mu \mathrm{M})$ on COX-2(A) and VCAM-1 (B) protein expression in TNF- $\alpha$-activated (10 ng/ml) HUVECs. The data were expressed as means \pm SEM $(n=3) * \mathrm{P}<0.05$ vs \#P $<0.05$ vs TNF- $\alpha$

Table 1: Inflammatory parameters measured in HUVECs pretreated with P. speciosa (PS, $25 \mu \mathrm{g} / \mathrm{ml})$ or quercetin (125 $\mu \mathrm{M})$ and exposed to TNF- $\alpha$ (10 ng/ml).

\begin{tabular}{ccccc}
\hline & Control & TNF- $\alpha$ & TNF- $\boldsymbol{\alpha}+$ PS & TNF- + Quercetin \\
\hline iNOS activity $(\mathrm{ng} / \mathrm{ml})$ & $0.23 \pm 0.03$ & $3.40 \pm 0.10^{*}$ & $2.68 \pm 0.02^{*} \#$ & $2.24 \pm 0.30^{* \#}$ \\
NO level $(\mu \mathrm{M})$ & $3.16 \pm 0.17$ & $17.53 \pm 0.16^{*}$ & $10.24 \pm 0.25^{*}$ & $6.83 \pm 0.20^{*} \#$ \\
ROS level $(\%$ of control) & $100.0 \pm 0.0$ & $182.2 \pm 1.7^{*}$ & $120.0 \pm 5.4 \#$ & $97.7 \pm 6.9 \#$ \\
\hline
\end{tabular}

*Different from control $(P<0.05)$; \#different from TNF- $\alpha$ group $(P<0.05)$.

\section{Intracellular iNOS activity, NO and ROS levels}

Exposure to TNF- $\alpha$ significantly elevated iNOS activity and NO levels $(P<0.05)$. Pretreatments of $P$. speciosa extract and quercetin similarly diminished the elevation of both parameters. HUVECs treated with TNF- $\alpha$ had significantly higher levels of intracellular ROS than the negative control. Pretreatment of the extract or quercetin significantly reversed the effect of TNF- $\alpha$ on intracellular ROS levels. No significant differences with regards to ROS levels were observed among the extract, quercetin, and negative control groups (Table 1).

\section{DISCUSSION}

Chromatographic analysis showed there to be the presence of quercetin in the extract. Ko et al. (2014) also reported the components of the phytochemical present in the Parkia speciosa empty pod extract. We attempted to analyze the phytochemical content in the extract via their method but failed.
They had described the presence of gallic acid, catechin, chlorogenic acid, quercetin, ellagic acid, kaempferol, vanillic acid, and epicatechinwithin their extract. Site and time of collection (season) could affect the composition of phytochemicals in plants. In particular, they analyzed ethanol extract without further fractionation through HPLC while in our study, we analyzed the ethyl acetate fraction of the ethanolic extract. This might explain the discrepancy in our findings. A recent study also demonstrated the presence of quercetin in Parkia speciosa empty pod methanol extract (Kamisah et al., 2017).

This study was a preliminary investigation with the objective of screening the anti-inflammatory of the $P$. speciosa empty pod extract in HUVECs. To the best of our knowledge, there is no single study that has reported the anti-inflammatory properties of this plant. The concentration of $P$. specios $a$ extract at $25 \mu \mathrm{g} / \mathrm{ml}$ was chosen based on its highest cell viability in HUVECs co-incubated with TNF- $\alpha$ and the use of quercetin as the positive control was because of its presence in the extract. TNF- $\alpha$ 
increased NF- $\mathrm{KB}$ p65 protein expression in HUVECs as similarly reported in other studies (Cao et al., 2009; Profumo et al., 2016). $\mathrm{NF}-\kappa \mathrm{B}$ protein complex is involved in several cellular responses to stimuli, such as free radicals, stress, and cytokines (Donato et al., 2015), associated with activation of adhesion molecules, chemokines, and cytokines (Valen et al., 2001). Exposure of cells to TNF- $\alpha$ causes phosphorylation of the NF- $\kappa B$ inhibitory protein, $\mathrm{I} \kappa \mathrm{B}$, which mediates its translocation to the nucleus and regulates the expression of numerous genes and proteins involved in inflammation (Lawrence, 2009). Activation of the NF- $\kappa$ B pathway activates the gene that encodes iNOS protein (Aktan, 2004), which is observed as enhanced iNOS protein expression and activity leading to increased NO production as per our study. P. speciosa and quercetin pretreatments had significantly decreased these parameters. The protective effects of the extract were most likely attributable to its polyphenolic content, especially that of quercetin. The effects of quercetin seemed to be more prominent earlier in the pathway $(\mathrm{NF}-\kappa \mathrm{B})$ than at the later stages (iNOS). Quercetin has been described to inhibit NF- $\kappa \mathrm{B}$ (Indra et al., 2013) and iNOS expression (Garcia-Mediavilla et al., 2007).

Activation of iNOS would further elevate NO (Sarath et al., 2014) and ROS production (Cook, 2006) in TNF- $\alpha$-induced cells as similarly observed during the state of stress (Kamisah et al., 2016). Increased production of NO may couple with ROS in the cells to form peroxynitrite radicals (Cook, 2006), which promote further damage to these cells. Both $P$. speciosa and quercetin reduced TNF- $\alpha$-induced NO levels but inhibited ROS production. The greater impact of both pretreatments on ROS could be also attributed to their potent antioxidant properties (Kamisah et al., 2013; Zhu et al., 2017) in addition to their antiinflammatory properties. Our recent study indicated that in vivo supplementation of $P$. speciosa reduced NADPH oxidase enzyme in hypertensive rats (Kamisah et al., 2017). This enzyme is a source of free radicals, especially superoxide anion (Klima et al., 2013). Quercetin was also reported to attenuate NADPH oxidase expression (Xiao et al., 2017).

COX-2 protein expression is upregulated in TNF- $\alpha$ induced cells. COX-2 is an enzyme for prostaglandin synthesis that is responsible in inflammation (Li et al., 2014). Upregulation of the enzyme by NF- $\kappa \mathrm{B}$ is partially responsible for inflammatory responses (Hsu et al., 2013). The extract and quercetin in our study exhibited decreasing the expression of NF-kB-associated downstream inducible enzymes, like iNOS and COX-2, as well as via upstream mechanisms of NF- $\mathrm{NB}$ by diminishing ROS and NO production (Hsu et al., 2013). Quercetin was demonstrated to inhibit COX-2 expression (Garcia-Mediavilla et al., 2007).

NO may also modulate endothelial cell adhesion molecule expression in cultured endothelial cells in vitro by various mechanisms. The upregulated expression of cell adhesion molecules on endothelial cells will alter the adhesive properties of vasculature, which implies a signal for HUVECs activation (Krieglstein and Granger, 2001). VCAM-1 is constitutively expressed in the vascular endothelium when induced by proinflammatory cytokines (Qi et al., 2010). In the current study, VCAM-1 expression was downregulated by $P$. speciosa and quercetin in TNF- $\alpha$-induced HUVECs, which was consistent with previous work (Bhaskar et al., 2016). VCAM-1 plays an important role in the early development of atherosclerosis (Bhaskar et al., 2016). Therefore, our findings suggest that $P$. speciosa extract may be beneficial for attenuating early progression of atherosclerosis. Anti-inflammatory properties of $P$. speciosa extract in the work presented here could be further explored in future studies in diseased states.

\section{CONCLUSION}

Parkia speciosa empty pod extract treatments attenuate TNF- $\alpha$-induced inflammatory responses in HUVECs by blocking the activation of NF- $\kappa \mathrm{B}$ p 65 , which leads to a reduction in iNOS, COX-2, and VCAM-1 expression as well as ROS and NO production. The effects were comparable to that of quercetin.

\section{ACKNOWLEDGMENTS}

The authors would like to acknowledge the financial support from the Universiti Kebangsaan Malaysia (UKM) grant (AP-2014-013) and technical help from Ms. Manali Haniti Mohd Zahid, Puan Nurul Hafizah Abas, En Fadhlullah Zuhair Japar Sidik, Puan Juliana Abdul Hamid, and Ms. Nurul Akmal Muhammad.

\section{CONFLICT OF INTEREST}

The authors declare that they have no conflict of interest.

\section{REFERENCES}

Aktan F. iNOS-mediated nitric oxide production and its regulation. Life Sci., 2004; 75:639-653.

Bhaskar S, Sudhakaran PR, Helen A. Quercetin attenuates atherosclerotic inflammation and adhesion molecule expression by modulating TLR-NF- $\kappa$ B signaling pathway. Cell Immunol., 2016; 310:131-140.

Cao LH, Lee YJ, Kang DG, Kim JS, Lee HS. Effect of Zanthoxylum schinifolium on TNF- $\alpha$-induced vascular inflammation in human umbilical vein endothelial cells. Vascul. Pharmacol., 2009; 50:200207.

Conde E, Giménez-Moyano S, Martín-Gómez L, Rodríguez M, Ramos ME, Aguado-Fraile E, Blanco-Sanchez I, Saiz A, García-Bermejo ML. HIF-1 $\alpha$ induction during reperfusion avoids maladaptive repair after renal ischemia/reperfusion involving miR127-3p. Sci. Rep., 2017; 7: 41099 .

Cook S. Coronary artery disease, nitric oxide and oxidative stress: the "Yin-Yang" effect--a Chinese concept for a worldwide pandemic. Swiss Med. Wkly., 2006; 136:103-113.

Díaz-Rivas JO, Herrera-Carrera E, Gallegos-Infante JA, RochaGuzmán NE, González-Laredo RF, Moreno-Jiménez MR, Ramos-Gómez M, Reynoso-Camacho R, Larrosa-Pérez M, Gallegos-Corona MA. Gastroprotective potential of Buddleja scordioides Kunth Scrophulariaceae infusions; effects into the modulation of antioxidant enzymes and inflammation markers in an in vivo model. J. Ethnopharmacol., 2015; 169:280-286.

Donato AJ, Morgan RG, Walker AE, Lesniewski LA. Cellular and molecular biology of aging endothelial cells. J. Mol. Cell. Cardiol., 2015; 89:122-135. 
García-Mediavilla V, Crespo I, Collado PS, Esteller A, Sánchez-Campos S, Tuñón MJ, González-Gallego J. The antiinflammatory flavones quercetin and kaempferol cause inhibition of inducible nitric oxide synthase, cyclooxygenase- 2 and reactive C-protein, and down-regulation of the nuclear factor kappaB pathway in Chang liver cells. Eur. J. Pharmacol., 2007; 557:221-229.

He Y, Yue Y, Zheng X, Zhang K, Chen S, Du Z. Curcumin, inflammation, and chronic diseases: how are they linked? Molecules, 2015; 20:9183-9213.

Hsu CC, Lien JC, Chang CW, Chang CH, Kuo SC, Huang TF. Yuwen02f1 suppresses LPS-induced endotoxemia and adjuvant-induced arthritis primarily through blockade of ROS formation, NFkB and MAPK activation. Biochem. Pharmacol., 2013; 85:385-395.

Indra MR, Karyono S, Ratnawati R, Malik SG. Quercetin suppresses inflammation by reducing ERK1/2 phosphorylation and NF kappa B activation in leptin-induced human umbilical vein endothelial cells (HUVECs). BMC Res. Notes, 2013; 6:275.

Kamisah Y, Ang SM, Othman F, Nurul-Iman BS, Qodriyah HM. Renoprotective effect of virgin coconut oil in heated palm oil dietinduced hypertensive rats. Appl. Physiol. Nutr. Metab,,2016; 41:10331038.

Kamisah Y, Othman F, Qodriyah HMS, Jaarin K. Parkia speciosaHassk.: A potential phytomedicine. Evid. Based Complement. Alternat Med., 2013; 2013:709028.

Kamisah Y, Zuhair JSF, Juliana AH, Jaarin K. Parkia speciosa empty pod prevents hypertension and cardiac damage in rats given $\mathrm{N}(\mathrm{G})$ nitro-1-arginine methyl ester. Biomed. Pharmacother., 2017; 96:291-298.

Klima L, Kawecka-Jaszcz K, Stolarz-Skrzypek K, Menne J, Fijorek K, Olszanecka A, Wojciechowska W, Bilo G, Czarnecka D. Structure and function of large arteries in hypertension in relation to oxidative stress markers. Kardiol. Pol., 2013; 71:917-923.

Ko HJ, Ang LH, Ng LT. Antioxidant activities and polyphenolic constituents of bitter bean Parkia speciosa. Int. J. Food Prop., 2014; 17:1977-1986.

Komolafe K, Olaleye TM, Omotuyi OI, Boligon AA, Athayde ML, Akindahunsi AA, Teixeira da Rocha JB. In vitro antioxidant activity and effect of Parkiabiglobosa bark extract on mitochondrial redox status. J. Acupunct. Meridian Stud., 2014; 7:202-210.

Krieglstein CF, Granger DN. Adhesion molecules and their role in vascular diseases. Am. J. Hypertens., 2001; 14:44S-54S.

Lawrence $\mathrm{T}$. The nuclear factor NF-kappa B pathway in inflammation. Cold Spring Harb. Perspect. Biol., 2009; 1:a001651.

Li L, Wang L, Wu Z, Yao L, Wu Y, Huang L, Liu K, Zhou X, Gou D. Anthocyanin-rich fractions from red raspberries attenuate inflammation in both RAW264. 7 macrophages and a mouse model of colitis. Sci. Rep., 2014; 4:6234.

Lim TK. 2012. Parkia speciosa, In: Edible Medicinal and NonMedicinal Plants, Volume 2 (Fruits), Netherlands: Springer 798-803.

Miranda KM, Espey MG, Wink DA. A rapid, simple spectrophotometric method for simultaneous detection of nitrate and nitrite. Nitric Oxide, 2001; 5:62-71.
Profumo E, Buttari B, D'Arcangelo D, Tinaburri L, Dettori MA, Fabbri D, Delogu G, Riganò R. The nutraceutical dehydrozingerone and its dimer counteract inflammation- and oxidative stress-induced dysfunction of in vitro cultured human endothelial cells: a novel perspective for the prevention and therapy of atherosclerosis. Oxid. Med. Cell. Longev., 2016; 2016:1246485.

Qi Y, Liang J, She ZG, Cai Y, Wang J, Lei T, Stallcup WB, Fu M. MCP-induced protein 1 suppresses TNF $\alpha$-induced VCAM-1 expression in human endothelial cells. FEBS Lett., 2010; 584:3065-3072.

Sarath TS, Waghe P, Gupta P, Choudhury S, Kannan K, Pillai AH, Harikumar SK, Mishra SK, Sarkar SN. Atorvastatin ameliorates arsenic-induced hypertension and enhancement of vascular redox signaling in rats. Toxicol. Appl. Pharmacol., 2014; 280:443-454.

Tuzcu Z, Orhan C, Sahin N, Juturu V, Sahin K. Cinnamon polyphenol extract inhibits hyperlipidemia and inflammation by modulation of transcription factors in high-fat diet-fed rats. Oxid. Med. Cell. Longev., 2017; 2017:1583098.

Valen G, Yan ZQ, Hansson GK. Nuclear factor kappa-B and the heart. J. Am. Coll. Cardiol., 2001; 38:307-314.

Wen YD, Wang H, Kho SH, Rinkiko S, Sheng X, Shen HM, Zhu YZ. Hydrogen sulfide protects HUVECs against hydrogen peroxide induced mitochondrial dysfunction and oxidative stress. PLoS One, 2013; 8:e53147.

Xiao L, Liu L, Guo X, Zhang S, Wang J, Zhou F, Liu L, Tang $\mathrm{Y}$, Yao P. Quercetin attenuates high fat diet-induced atherosclerosis in apolipoprotein E knockout mice: A critical role of NADPH oxidase. Food Chem. Toxicol., 2017; 105:22-33.

Xie C, Reusse A, Dai J, Zay K, Harnett J, Churg A. TNF-alpha increases tracheal epithelial asbestos and fiberglass binding via a NFkappa B-dependent mechanism. Am. J. Physiol. Lung Cell. Mol. Physiol., 2000; 279:L608-L614.

Zhou-Stache J, Buettner R, Artmann G, Mittermayer C, Bosserhoff AK. Inhibition of TNF-alpha induced cell death in human umbilical vein endothelial cells and Jurkat cells by protocatechuic acid. Med. Biol. Eng. Comput., 2002; 40:698-703.

Zhu X, Li N, Wang Y, Ding L, Chen H, Yu Y, Shi X. Protective effects of quercetin on UVB irradiation-induced cytotoxicity through ROS clearance in keratinocyte cells. Oncol. Rep., 2017; 37:209-218.

\section{How to cite this article:}

Mustafa NH, Ugusman A, Jalil J, Kamisah Y. Anti-inflammatory property of Parkia speciosa empty pod extract in human umbilical vein endothelial cells. J App Pharm Sci, 2018; 8 (01): 152-158. 